\title{
For a Safer Working Environment with Hydrofluoric Acid in Iraqi Industrial Plants
}

\author{
Ali Abd Ali'1, Naser Shaalan², Wedad Al-Dahhan'1, Emad Yousif ${ }^{1}$ \\ ${ }^{1}$ Department of Chemistry, College of Science, Al-Nahrain University, Baghdad, Iraq \\ ${ }^{2}$ Department of Chemistry, College of Science for Women, University of Baghdad, Baghdad, Iraq \\ Email:emad_yousif@hotmail.com
}

How to cite this paper: Abd Ali, A., Shaalan, N., Al-Dahhan, W. and Yousif, E. (2016) For a Safer Working Environment with Hydrofluoric Acid in Iraqi Industrial Plants. Open Journal of Safety Science and Technology, 6, 77-80.

http://dx.doi.org/10.4236/ojsst.2016.64007

Received: September 16, 2016

Accepted: December 2, 2016

Published: December 7, 2016

Copyright $\odot 2016$ by authors and Scientific Research Publishing Inc. This work is licensed under the Creative Commons Attribution International License (CC BY 4.0).

http://creativecommons.org/licenses/by/4.0/

\begin{abstract}
Hydrofluoric acid has been one of the important chemicals in the industry. In Iraq, there is a considerable consumption of it in petrochemicals and detergents industry. However, so far, there is no genuine evaluation for the hazards and any prospective procedures to minimise the risk of it. In this regard, we show here some accidents took place in some industrial amenities in Iraq and other Arabic countries. In addition, there is an elaborated description of the degree of risk, safety practices, and some feasible treatments for hydrofluoric acid burns and inhalations.
\end{abstract}

\section{Keywords}

Hydrofluoric Acid, Hazards, Safety, Feasible Treatments

\section{Introduction}

Hydrofluoric acid (HF) is one of the most hazardous chemicals due to its toxicological effects to skin, and respiratory system [1]. Unlike other hydrohalide acids, e.g. Hydrochloric acid, $\mathrm{HF}$ does not dissociate completely in water to give hydrogen ions $\left(\mathrm{H}^{+}\right)$ and fluoride ions $\left(\mathrm{F}^{-}\right)$owing to the strong electrostatic interactions between fluorine and hydrogen. In reality, the effect of $\mathrm{HF}$ acidity becomes less pronounced if dissolved in water. Nevertheless, even at low concentrations HF can cause severe burns to skin accompanied by whitening of skin [2] as shown in Figure 1.

In some cases, moderate concentrations of $\mathrm{HF}(\sim 50 \%)$ can lead to an extremely severe burns that may cause death if the burnt area is more than $20 \%$ of the total body area [3].

The skin damage is completely attributed to the corrosive effect of HF. The chemical dissociation of it gives $\mathrm{F}^{-}$and $\mathrm{H}^{+}$, and the latter depletes the skin tissue to open up a 
way for the fluoride $\mathrm{F}^{-}$penetration inside the skin and to be combined with $\mathrm{Ca}^{2+}$ as shown in Figure 2.

As mentioned earlier, there might be a minor effect on skin if HF was diluted. Albeit, the prolonged exposure, delay in symptoms' appearance, and no treatment can give the same severe effect of moderate or highly concentrated HF.

Inhalation of HF vapours may also be very harmful to respiratory system, namely, pulmonary edema, and laryngospasm. Ingestion also can occur and cause poisoning then death.

All of the above adverse effects of HF necessitate raising this issue and suggesting reliable safety measures, precautions, and any possible treatments whenever accidents occur.

\section{Potential Risks and Examples}

As mentioned earlier, there might be a minor effect on skin if HF was diluted. Albeit, the prolonged exposure, delay in symptoms' appearance, and no treatment can give the same severe effect of moderate or highly concentrated HF. Inhalation of HF vapours may also be very harmful to respiratory system, namely, pulmonary edema, and laryngospasm. Ingestion also can occur and cause poisoning then death. Along with our previous case study on safety protocols [4], we believe that all of the above adverse effects of HF necessitate raising this issue and suggesting reliable safety measures, precautions,

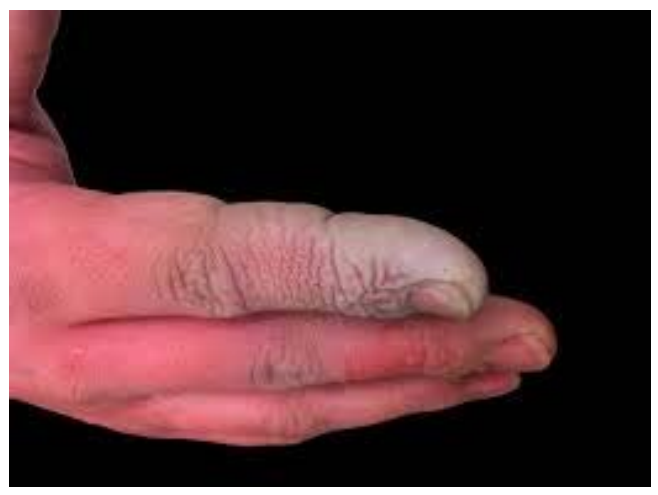

Figure 1. HF burns to skin with a moderately to highly concentrated HF.

\section{HYDROFLUORIC ACID}

The penetration capacity of the

Fluoride ion and the Acid

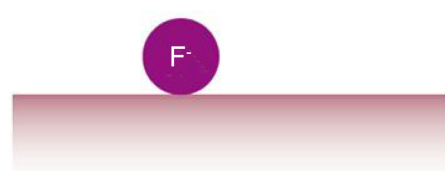

Only Fluoride ions

No penetration $=$ No scattering of

the toxic fluoride ions

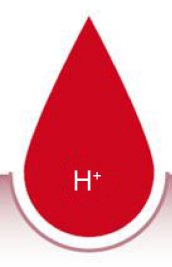

Only Acid injury occurs

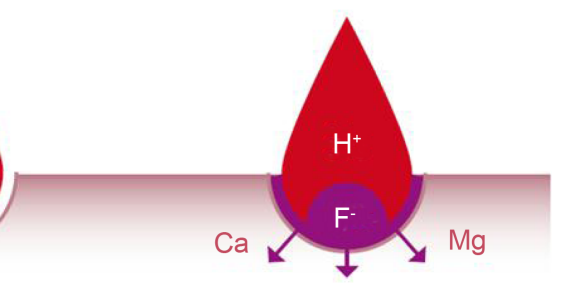

Both Acid and Fluoride ions The acid opens up for the toxic fluoride ions to spread out into the body

Figure 2. The penetration of $\mathrm{F}^{-}$into the skin via the help of $\mathrm{H}^{+}$. 
and any possible treatments whenever accidents occur.

\section{Safety Precautions and Management}

- Conducting a regular inspections for reactors, valves, reservoirs, etc. in order to avoid any possible accidents.

- Reading and understanding the Safety Data Sheet (SDS) of HF by chemists/chemical engineers in advance.

- Preparing a reasonable risk assessment form which includes all the possible risks, determining the risk score, and how to control or prevent any incident.

- Asking all staff members who are working with HF to read the risk assessment form carefully and sign it.

- Wearing PPE (gloves, goggles, and lab coats) is compulsory at all times with no excuses.

- Testing ventilation systems and installing oxygen sensors and they should be checked regularly.

- Providing a first aid kit in the vicinity of production facility.

\section{Treatment}

For skin burns, the affected area must be irrigated with a tap water for at least $10-15$ minutes, then apply a copious amount of calcium gel (Figure 3). Physicians recommend doing that every 30 minutes. If HF concentration was high and the casualty is still suffering from pain, then an intra-arterial fusion of calcium must be given. They must take $50 \mathrm{~mL}$ of calcium gluconate (4\%) during a period of 4 hours over a course of 12 hours. However, there might be some side effects for this treatment, for instance, hypercalcemia [5] [6] [7] [8].

For eyes treatment, they should be thoroughly washed with water (eye washed is highly preferred). Thereafter, they either use few drops of calcium gluconate eye drops $(1 \%-10 \%)$ or seek for a medical advice immediately by an ophthalmologist.

\section{Conclusion}

In the light of the present case study, we would like to emphasise the importance of safety in every industrial plant in Iraq. Offering a reasonably safe and low-risk environment

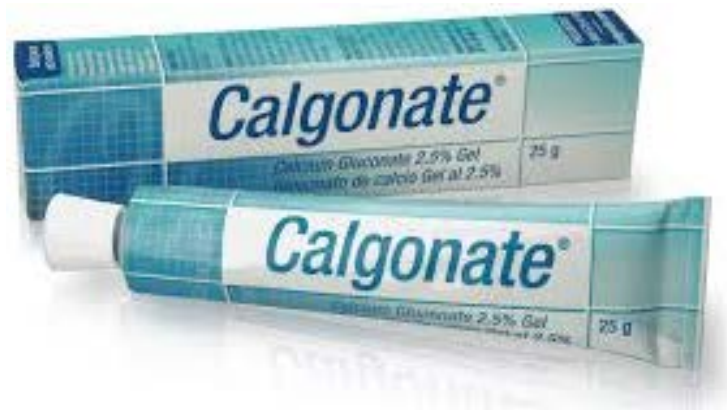

Figure 3. The calcium gel for treating HF burns. 
should be the first priority. Furthermore, working with highly corrosive, and toxic chemicals like HF must be minimised and controlled. A set of procedures and protocols must be put and followed literally and strictly to avoid any potential damage to people and facilities.

\section{Recommendations}

In every industrial amenity or laboratory, there must be a full risk assessment folder which contains all risk assessment forms for each chemical reaction performed in these premises. Additionally, supervisors or employers must allow their staff members to access the risk assessment and have some training to control risks and minimise it.

\section{References}

[1] Caravati, M. (1988) Acute Hydrofluoric Acid Exposure. American Journal of Emergency Medicine, 6, 143-150. https://doi.org/10.1016/0735-6757(88)90053-8

[2] HSDB. Hydrogen Fluoride, in Hazardous Substances Data Bank, National Library of Medicine, Bethesda, MD. http://www.nlm.nih.gov

[3] Dünser, M.W., Öhlbauer, M., Rieder, J., Zimmermann, I., Ruatti, H., Schwabegger, A.H., Bodrogi, F., Huemer, G.M., Friesenecker, B.E., Mayr, A.J. and Lirk, P. (2004) Critical Care Management of Major Hydrofluoric Acid Burns: A Case Report, Review of the Literature, and Recommendations for Therapy. Burns, 30, 391-398.

https://doi.org/10.1016/j.burns.2004.01.005

[4] Shireen, R., Al-Dahhan, W., Al-Zuhairi, A., Hussein, F., Rodda, K. and Yousif, E. (2016) Fire and Explosion Hazards Expected in a Laboratory. Journal of Laboratory Chemical Education, 4, 35-37.

[5] Kohnlein, H. and Achinger, R. (1982) A New Method of Treatment of Hydrofluoric Acid burns Of the Extremities. Annales de Chirurgie Plastique Esthétique, 6, 297-305.

[6] Lin, T., Tsai, C. and Lin, S. (2001) Continuous Intra-Arterial Infusion Therapy in Hydrofluoric Acid Burns. Journal of Occupational and Environmental Medicine, 42, 892. https://doi.org/10.1097/00043764-200009000-00008

[7] Nguyen, L., Mohr, W., Ahrenholz, D., et al. (2004) Treatment of Hydrofluoric Acid Burns to the Face by Carotid Artery Infusion of Calcium Gluconate. Journal of Burn Care \& Rehabilitation, 25, 421. https://doi.org/10.1097/01.BCR.0000138288.15403.BA

[8] Thomas, D., Jaeger, U., Sagoschen, I., et al. (2009) Intar-Arterial Calcium Gluconate Treatment after Hydrofluoric Acid Burn of the Hand. CardioVascular and Interventional Radiology, 32, 155. https://doi.org/10.1007/s00270-008-9361-1 
Submit or recommend next manuscript to SCIRP and we will provide best service for you:

Accepting pre-submission inquiries through Email, Facebook, LinkedIn, Twitter, etc. A wide selection of journals (inclusive of 9 subjects, more than 200 journals)

Providing 24-hour high-quality service

User-friendly online submission system

Fair and swift peer-review system

Efficient typesetting and proofreading procedure

Display of the result of downloads and visits, as well as the number of cited articles

Maximum dissemination of your research work

Submit your manuscript at: http://papersubmission.scirp.org/

Or contact ojsst@scirp.org 